\title{
Research on Evaluation of Zhejiang Cultural Tourism Competitiveness-Based on Data Analysis of 11 Cities
}

\author{
Xu Li \\ College of International Finance and Trade, Zhejiang Yuexiu University, Shaoxing, Zhejiang, 312000, China
}

\begin{abstract}
This paper takes 11 cities in Zhejiang Province as the research object and divides the competitiveness of cultural tourism into three dimensions: cultural tourism supply competitiveness, cultural tourism demand competitiveness, and cultural tourism support competitiveness. A total of 23 indicators were selected, and the entropy method, GIS and other methods were used to evaluate the cultural tourism competitiveness of cities in Zhejiang Province. The results illustrate that Hangzhou has the strongest competitiveness, Ningbo, Wenzhou, Jinhua, and Jiaxing are in the second echelon, Taizhou, Shaoxing, Huzhou, and Zhoushan have average competitiveness, and Lishui and Quzhou have the weakest competitiveness. Through further analysis of the characteristics of indicators in each dimension, combined with the conditions of Zhejiang Province and each city, suggestions for enhancing their respective cultural tourism competitiveness are put forward.
\end{abstract}

Keywords: Cultural tourism industry, Competitiveness evaluation, Entropy method, Zhejiang Province.

\section{Introduction}

Nowadays, China has entered a stage of high-quality development. Under the background of a large domestic cycle and a dual cycle of international and domestic, the cultural and tourism industry is an important market that releases new demand and stimulates new consumption. Zhejiang is a major tourism province. In 2019, the added value of the province's tourism industry was 491.4 billion yuan, accounting for $7.9 \%$ of the province's GDP. The province's tourism industry accounts for $10.5 \%$ of the total employment population, and its comprehensive contribution to the province's GDP reaches 18.7\%. In the 14th Five-Year Plan of Zhejiang Province, Zhejiang aims to become a modern tourism province. The cultural industry and tourism industry are Zhejiang's trilliondollar industries. By 2025, it is expected that the province will receive more than 400 million overnight domestic tourists. The total output of the tourism industry is 1.78 trillion yuan. Zhejiang is rich in tourism resources. At the same time, the rapid transformation of national strategic dividends such as the construction of the "Common Prosperity Demonstration Zone", the "Belt and Road", and the high-quality integrated development of the Yangtze River Delta has provided new impetus for the development of the tourism industry. However, with the rapid development of the cultural and tourism industry, the integration of the cultural and tourism industry and other related industries is not enough. The problem of homogenization of tourism products between cities is still prominent, service levels and quality are uneven, resource development planning and implementation The effect is quite different. Therefore, studying the evaluation of Zhejiang's cultural tourism competitiveness will help local governments, tourism management and other relevant departments and organizations to solve the relevant development dilemmas, provide basic data support for the development of cultural tourism in local cities, and facilitate further measures. This has positive practical significance for promoting the high-quality development of urban cultural tourism in Zhejiang.

\section{Literature Review}

\subsection{Competitiveness-Related Theories}

Domestic and foreign scholars have analyzed competitiveness from multi-disciplinary and multi-level research such as economics, sociology, and geography. Among them, the "Porter Diamond Theory Model" proposed by Harvard Business School management scientist Michael Porter in 1990 is often used in competitiveness analysis. It believes that whether a country's specific industry is competitive depends on the six elements of production factors, demand conditions, related and supportive industries, corporate strategy and corporate structure and competition, opportunity and government work together. The first four are key elements and the second two are auxiliary elements. In the research on competitiveness related to cities, Lever and Turok (1999) emphasized that urban competitiveness refers to the ability of a city to provide products and services that meet the needs of regional, domestic and international markets, and an ability to increase the actual income of citizens, improve the quality of life of citizens and promote the ability of sustainable urban development.

\subsection{The Theory of Cultural Tourism Competitiveness}

Dwyer and Kim (2003) believe that tourism competitiveness is manifested in a destination's ability to provide products and services better than other destinations in those aspects that tourists consider experience to be very important. Gilbert (1990) proposed a differentiated strategic model of destination positioning, and believed that destinations should obtain unique advantages in tourism products through differentiated positioning; D Hauteserre (2000) believed that the tourism competitiveness of a destination can be defined as The destination's ability to maintain its market position and market share, or to improve its tourism market position and increase its market share. The composition aspect of cultural 
tourism competitiveness. Internationally, the World Economic Forum (WEF) publishes a global tourism competitiveness report every two years. The most recent one was in 2019. It mainly consists of several aspects, namely the tourism environment (business environment, safety level, health, human resources), information and communication technology support, etc.), tourism policies and conditions (tourism priority, degree of internationalization, price competitiveness, environmental sustainability), infrastructure (aviation infrastructure, ground and port transportation, tourism service facilities), natural and cultural resources (natural resources, cultural resources and business tourism);Domestically, Beijing Union University and Social Science Literature Publishing House released the "China Urban Leisure and Tourism Competitiveness Report 2020", which mainly focuses on basic elements, efficiency, innovation and maturity Competitiveness measurement in terms of degree.

Scholars at home and abroad have also carried out demonstrations on the competitiveness of tourist destinations from multiple angles. American scholar Johnson proposed the definition of niche theory. The niche of tourist destinations means that a certain tourist destination in a region has a certain status and function in the development process, and at the same time Interacting with the surrounding environment and other tourist destinations, the research of many scholars is basically based on a similar framework. Crouch and Ritchie (1999) believe that tourism competition can be defined from three aspects, which are the perspectives of residents' welfare, social prosperity and sustainable development. Ma Yong and Dong Guan (1997) were the first to discuss this issue in China. They mainly study the potential for sustainable development in tourism competition, mainly from the potential security of tourism resources, the potential support of the regional social economy, and the potential carrying capacity of the regional environmental capacity; Zhang Heqing et al (2012) used data from 67 counties in Guangdong Province to select 19 indicators from factors such as factor competitiveness, market competitiveness, management competitiveness, and development competitiveness to establish tourism competitiveness evaluation Index system; Song Rui (2020) pointed out that tourism total factor productivity, tourism international competitiveness, tourism trade balance, balanced regional tourism development differences, tourist satisfaction, and tourism market vitality are where urban tourism competitiveness lies; Jie Ruijin, etc. (2020) ) Taking Shanxi Province as an example, using a gray scale evaluation model to explain and evaluate the competitiveness of the tourism industry in terms of tourism performance, resources and development support; Xu Chunhong, Su Weiying (2021) take the Hangzhou Bay area and the Guangdong-Hong KongMacao Bay Area Comparing the indicators of tourism development in the district, using the PROMETHEE method from the basic modules related to resources and industrial performance and the development modules related to innovation, coordination, green, openness and sharing, establish indicators to measure the competitiveness of 18 cities.

In addition, from the perspective of the research objects and scope, the research on the tourism competitiveness of domestic cities, some are national capital cities or major national tourism cities, and some are based on regions, mainly inter-regional comparisons or intra-regional comparisons, such as the Yangtze River Delta and the Pearl River Delta, the Hangzhou Bay and the Guangdong-Hong Kong-Macao Greater Bay Area, as well as areas divided by orientation. Shi Xiangxiang (2019) studied the tourism data of 80 prefecturelevel cities in the central region from 2011 to 2015, as well as the comparison of county tourism cities in the region. $\mathrm{Li}$ Chunying et al. (2020) studied 84 county-level cities along the coast and inland of Fujian Province. From the perspective of the scope of research, most of them focus on the overall competitiveness evaluation of tourism. Some scholars also study the competitiveness of tourism in sub-fields, such as health tourism, rural tourism, eco-tourism, sports tourism, marine tourism, ancient capital tourism, exhibition tourism, Red tourism, inbound tourism, etc.

\section{Research Design}

\subsection{Construction of Cultural Tourism Competitiveness Evaluation System}

Combining existing scholars' research and the current status of tourism development in the locality, this article builds an evaluation system of urban cultural tourism competitiveness based on the comprehensiveness, scientificity, availability, traceability, and standardization of the index system. 23 indicators are selected mainly from the three dimensions of cultural tourism supply competitiveness, cultural tourism demand competitiveness, and cultural tourism support competitiveness. The competitiveness dimension of cultural tourism supply mainly considers the input elements of the tourism market, including tourism resources, such as the number of A-level tourist attractions, the number of tourist hotels and other conventional indicators, as well as elements that may generate tourism motivation, such as culture, sports, and health. There are a total of 8 indicators in this dimension; the competitiveness of cultural tourism demand is mainly reflected in output, including domestic and foreign tourist income and its growth rate. There are 6 indicators in this dimension; the support of cultural tourism is mainly related to local People's income, consumption demand, transportation capacity, ecological environment, etc. are related to 9 indicators in this dimension, and the above construction of the tourism competitiveness evaluation system, shown in Table 1.

Table1: Competitiveness Evaluation Index System

\begin{tabular}{|c|c|}
\hline dimension & Index \\
\hline $\begin{array}{l}\text { Touris } \\
\text { compe }\end{array}$ & $\begin{array}{l}\text { Number of scenic spots above level A (C1), number of star- } \\
\text { rated hotels (C2), number of travel agencies (C3), public } \\
\text { budget for culture, tourism and sports media (10,000 yuan) } \\
\text { (C4), number of stadiums (C5), number of theaters and } \\
\text { theaters (C6), public library collections (ten thousand } \\
\text { volumes) (C7), number of hospital beds (C8) }\end{array}$ \\
\hline $\begin{array}{c}\text { Tourism } \\
\text { demand } \\
\text { competitiveness }\end{array}$ & $\begin{array}{l}\text { Inbound tourists (person-times) }(\mathrm{C} 9) \text {, inbound tourism } \\
\text { revenue (ten-thousand dollars) (C10), domestic tourists } \\
(10,000 \text {-person trips) }(\mathrm{C} 11) \text {, domestic tourism revenue } \\
(100 \text { million yuan) }(\mathrm{C} 12) \text {, domestic tourist growth rate }(\%) \\
(\mathrm{C} 13) \text {, domestic tourism revenue growth rate\% }(\mathrm{C} 14)\end{array}$ \\
\hline , & $\begin{array}{l}\text { Per capita disposable income (yuan) }(\mathrm{C} 15) \text {, total social } \\
\text { consumer goods }(100 \text { million yuan) }(\mathrm{C} 16) \text {, the proportion } \\
\text { of tertiary industry in GDP }(\%)(\mathrm{C} 17) \text {, total passenger } \\
\text { traffic }(10,000)(\mathrm{C} 18) \text {, number of buse }(\mathrm{C} 19) \text {, number of } \\
\text { taxis }(\mathrm{C} 20) \text {, green coverage area (ha) }(\mathrm{C} 21) \text {, sewage } \\
\text { treatment rate }(\%)(\mathrm{C} 22) \text {, the proportion of days with good } \\
\text { air quality }(\%)(\mathrm{C} 23)\end{array}$ \\
\hline
\end{tabular}




\subsection{Data Sources and Basic Information}

The data sources are mainly the website of Zhejiang Provincial Department of Culture and Tourism, the "2020 Zhejiang Statistical Yearbook", the statistical yearbooks of counties and cities in Zhejiang, and the statistical bulletin of national economic and social development of all cities in Zhejiang. The cut-off point is December 2019. Table 2 displays the overall tourism situation of the 11 cities in Zhejiang Province in 2019, including the number of inbound tourists, inbound tourism income, the number of domestic tourists, and the income of domestic tourists, sorted by domestic tourism income per capita. The top 3 are Hangzhou, Ningbo, and Zhoushan. Table 3 shows the number of A-level tourist attractions in 11 cities. There are a total of 798 scenic spots in the province, including 18 5A scenic spots, $2174 \mathrm{~A}$ scenic spots, and 446 3A scenic spots. Hangzhou, Taizhou, and Jiaxing are the top 3 scenic spots in total. Table 4 shows the main indicators of culture and health in 11 cities. Jiaxing has the most sports venues, followed by Taizhou and Huzhou. There is a big gap between theaters and music halls, with 119 in Hangzhou, and only 9 in Lishui and Wenzhou. Hangzhou, Ningbo and Wenzhou have better sanitary conditions.

It can be seen that there is a significant gap in tourism income among the 11 cities in Zhejiang Province from the perspectives of domestic, foreign, and per capita. Although each city has 5A scenic spots, except for Hangzhou and Zhoushan, the number of urban scenic spots is relatively close, but the cultural and sanitary conditions are quite different. In addition, economic conditions and ecological environment affect the competitiveness of urban cultural tourism. Therefore, it is very necessary to evaluate Zhejiang's cultural tourism competitiveness through calculation.

Table2: The basic tourism situation of cities in Zhejiang Province in 2019

\begin{tabular}{|c|c|c|c|c|c|c|c|}
\hline & City & $\begin{array}{l}\text { Inbound tourists } \\
\text { (person-times) }\end{array}$ & $\begin{array}{l}\text { Inbound tourism } \\
\text { revenue (ten- } \\
\text { thousand dollars) }\end{array}$ & $\begin{array}{c}\text { Domestic tourists } \\
\text { (ten-thousand } \\
\text { person-times) }\end{array}$ & $\begin{array}{l}\text { Domestic tourism } \\
\text { revenue (100 } \\
\text { million yuan) }\end{array}$ & $\begin{array}{l}\text { Per capita inbound } \\
\text { (USD) }\end{array}$ & $\begin{array}{c}\text { Per capita } \\
\text { domestic (yuan) }\end{array}$ \\
\hline 1 & Hangzhou & 1133143 & 73659 & 20700 & 3954 & 650.04 & 1910.14 \\
\hline 3 & Zhoushan & 156252 & 8511 & 7025 & 1012 & 544.70 & 1440.57 \\
\hline 4 & Jiaxing & 571130 & 31157 & 11971 & 1401 & 545.53 & 1170.33 \\
\hline 5 & Huzhou & 259250 & 14984 & 13198 & 1519 & 577.97 & 1150.93 \\
\hline 6 & Shaoxing & 152500 & 7360 & 11473 & 1302 & 482.62 & 1134.84 \\
\hline 7 & Wenzhou & 583884 & 31929 & 13670 & 1529 & 546.84 & 1118.51 \\
\hline 8 & Taizhou & 138754 & 4614 & 13156 & 1467 & 332.53 & 1115.08 \\
\hline 9 & Jinhua & 889269 & 53212 & 13913 & 1543 & 598.38 & 1109.03 \\
\hline 10 & Lishui & 11888 & 494 & 7795 & 781 & 415.55 & 1001.92 \\
\hline \multirow[t]{2}{*}{11} & Quzhou & 12900 & 593 & 7869 & 595 & 459.69 & 756.13 \\
\hline & Total & 4671121 & 266823 & 134717 & 17406 & & \\
\hline
\end{tabular}

※Data Sources,2020 Zhejiang Statistical Yearbook

Table 3: Distribution of A-level tourist attractions in Zhejiang Province by cities

\begin{tabular}{|c|c|c|c|c|c|c|}
\hline City & $5 \mathrm{~A}$ & $4 \mathrm{~A}$ & $3 \mathrm{~A}$ & $2 \mathrm{~A}$ & $\mathrm{~A}$ & A or above \\
\hline Hangzhou & 3 & 41 & 43 & 11 & 0 & 98 \\
\hline Ningbo & 2 & 32 & 28 & 0 & 0 & 62 \\
\hline Huzhou & 1 & 23 & 51 & 0 & 0 & 75 \\
\hline Lishui & 1 & 22 & 33 & 5 & 0 & 61 \\
\hline Jinhua & 1 & 20 & 48 & 5 & 0 & 74 \\
\hline Wenzhou & 1 & 19 & 51 & 4 & 0 & 75 \\
\hline Shaoxing & 1 & 18 & 33 & 27 & 1 & 80 \\
\hline Quzhou & 2 & 13 & 44 & 4 & 0 & 63 \\
\hline Jiaxing & 3 & 10 & 40 & 31 & 0 & 84 \\
\hline Zhoushan & 1 & 4 & 15 & 10 & 7 & 37 \\
\hline Total & 18 & 217 & 446 & 109 & 8 & 798 \\
\hline
\end{tabular}

※Data source: Zhejiang Provincial Department of Culture and Tourism website

Table 4: Main Indicators of Culture and Public Healthy by City (2019)

\begin{tabular}{|c|c|c|c|c|c|}
\hline City & $\begin{array}{l}\text { Number of Sports } \\
\text { Grounds and } \\
\text { Gymnasiums (unit) }\end{array}$ & $\begin{array}{c}\text { Number of Theaters and } \\
\text { Music Halls (unit) }\end{array}$ & $\begin{array}{c}\text { Total Collections of } \\
\text { Books in Public } \\
\text { Libraries (10000 copies) }\end{array}$ & $\begin{array}{l}\text { Number of Health } \\
\text { Institutions (unit) }\end{array}$ & $\begin{array}{c}\text { Number of Beds in } \\
\text { Health Institutions (bed) }\end{array}$ \\
\hline Hangzhou & 27 & 119 & 2557 & 343 & 79957 \\
\hline Ningbo & 22 & 15 & 1243 & 180 & 37354 \\
\hline Wenzhou & 36 & 9 & 1377 & 147 & 38313 \\
\hline Jiaxing & 66 & 70 & 987 & 87 & 23744 \\
\hline Huzhou & 45 & 40 & 285 & 70 & 16925 \\
\hline Shaoxing & 25 & 10 & 644 & 89 & 22001 \\
\hline Jinhua & 14 & 73 & 530 & 145 & 30305 \\
\hline Quzhou & 5 & 24 & 316 & 90 & 13363 \\
\hline Zhoushan & 8 & 18 & 235 & 34 & 5632 \\
\hline Taizhou & 49 & 53 & 869 & 133 & 27762 \\
\hline Lishui & 16 & 9 & 272 & 56 & 13097 \\
\hline
\end{tabular}




\subsection{Research Methods}

The methods of analyzing competitiveness mainly include analytic hierarchy process, factor analysis, principal component analysis, cluster analysis, fuzzy comprehensive evaluation, gray correlation method, entropy weight method, input-output efficiency analysis and other methods. For the data collected by the tourism competitiveness evaluation system, the main research methods adopted in this paper are entropy method and GIS spatial analysis.

\subsubsection{Entropy method}

Entropy method is a kind of objective weighting method, which can determine the weight of each indicator according to the amount of information contained in each indicator, and is widely used in the process of economic development quality evaluation. Based on the index system and data characteristics constructed in this article, and the excellent properties of the entropy method itself, this article finally uses the entropy method to determine the weights. The specific calculation process is as follows:

\section{Step1: data standardization}

Due to the differences in the dimensions and positive and negative orientations of the indicators, the data needs to be standardized. In order to make the standardized data value between $[0,1]$, the standardized formula adopted in this paper is:

$$
v_{i j}=\frac{x_{i j}-\min \left(x_{j}\right)}{\max \left(x_{j}\right)-\min \left(x_{j}\right)}, i=1,2, \cdots, \mathrm{n} ; \mathrm{j}=1,2, \cdots, \mathrm{m}
$$

Among them, $x_{i j}$ is the value of object $\mathrm{i}$ on index $\mathrm{j}, \max x_{j}$ is the maximum value of index $\mathrm{j}, \min x_{j}$ is the minimum value of index $\mathrm{j}, v_{i j}$ and is the standardized value of object $\mathrm{i}$ on index $\mathrm{j}$.

Step 2: All indicators are quantified at the same time

Calculate the proportion of the index value of the object $i$ under the jth index $p_{i j}$, namely:

$$
p_{i j}=\frac{v_{i j}}{\sum_{i=1}^{n} v_{i j}}
$$

Step 3: Calculate the entropy value of index $\mathrm{j}, e_{j}$, the specific formula is:

$$
e_{j}=-\frac{l}{\ln n} \sum_{i=1}^{n} p_{i j} \cdot \ln p_{i j}
$$

Step 4: Calculate the coefficient of difference of index $\mathrm{j}, d_{j}$. It reflects the information utility value of index $j$, and the specific formula is:

$$
d_{j}=l-e_{j}
$$

Step 5: Calculate the weight of index $\mathrm{j}, w_{j}$, the calculation formula is

$$
w_{j}=-\frac{d_{j}}{\sum_{i=1}^{n} d_{j}}
$$

Step 6: According to the obtained index weight, the comprehensive score of the evaluated object $\mathrm{i}$ can be obtained as:

$$
F_{i}=\sum_{j=1}^{m} w_{j} \cdot v_{i j}
$$

\subsubsection{GIS Visualization analysis}

The ArcGIS software is mainly used here, based on the evaluation and analysis of Zhejiang's urban tourism competitiveness system. By making GIS spatial maps, visually present and analyze the tourism competitiveness of 11 cities in Zhejiang from geographic space, and classify the strengths and weaknesses.

\section{Results and Discussion}

\begin{tabular}{|c|c|c|c|c|c|}
\hline Index & Weight & Index & Weight & Index & Weight \\
\hline $\mathrm{C} 1$ & 0.016605435 & C9 & 0.048994902 & $\mathrm{C} 17$ & 0.03657578 \\
\hline $\mathrm{C} 2$ & 0.047559299 & $\mathrm{C} 10$ & 0.054975711 & $\mathrm{C} 18$ & 0.046413045 \\
\hline $\mathrm{C} 3$ & 0.08087433 & $\mathrm{C} 11$ & 0.032210034 & C19 & 0.058158841 \\
\hline $\mathrm{C} 5$ & 0.041374619 & $\mathrm{C} 13$ & 0.014339286 & $\mathrm{C} 21$ & 0.017174566 \\
\hline C6 & 0.076152641 & $\mathrm{C} 14$ & 0.013755111 & $\mathrm{C} 22$ & 0.070996896 \\
\hline $\mathrm{C} 7$ & 0.055734442 & $\mathrm{C} 15$ & 0.025478083 & $\mathrm{C} 23$ & 0.027749833 \\
\hline $\mathrm{C} 8$ & 0.034508906 & $\mathrm{C} 16$ & 0.034726956 & & \\
\hline
\end{tabular}

According to the entropy method, by analyzing the basic data of 11 cities in Zhejiang, the weights of 23 indicators of Zhejiang's cultural tourism competitiveness can be obtained as shown in Table 5 as bellows:

Table 5: Index weight

The final cultural tourism competitiveness scores of 11 citiesare shown in Table 6 as follows:

Table6: Comprehensive competitiveness score of urban cultural tourism

\begin{tabular}{cccccc}
\hline City & Score & Rank & City & Score & Rank \\
Hangzhou & 0.87126136 & 1 & Shaoxing & 0.225291365 & 7 \\
Ningbo & 0.522374495 & 2 & Huzhou & 0.200152334 & 8 \\
Wenzhou & 0.420646449 & 3 & Zhoushan & 0.198713373 & 9 \\
Jinhua & 0.366307949 & 4 & Lishui & 0.14543107 & 10 \\
Jiaxing & 0.32933626 & 5 & Quzhou & 0.091791135 & 11 \\
Taizhou & 0.244654428 & 6 & Average & 0.328723656 & \\
\hline
\end{tabular}

It can be seen that Hangzhou has the highest score, and Quzhou has the lowest score. Taking the average value (0.328723656) as the dividing line, the cities with the average value above are Hangzhou, Ningbo, Wenzhou, Jinhua, and Jiaxing. Hangzhou has the second highest score. 1.66 times, in the absolute core position in Zhejiang Province. Ningbo, Wenzhou, Jinhua, and Jiaxing are in the second echelon with strong competitiveness. Taizhou, Shaoxing, Huzhou, and Zhoushan are generally competitive, while Lishui and Quzhou are in a state of weaker competitiveness. The specific geographical distribution is as Figure 1 shows. 


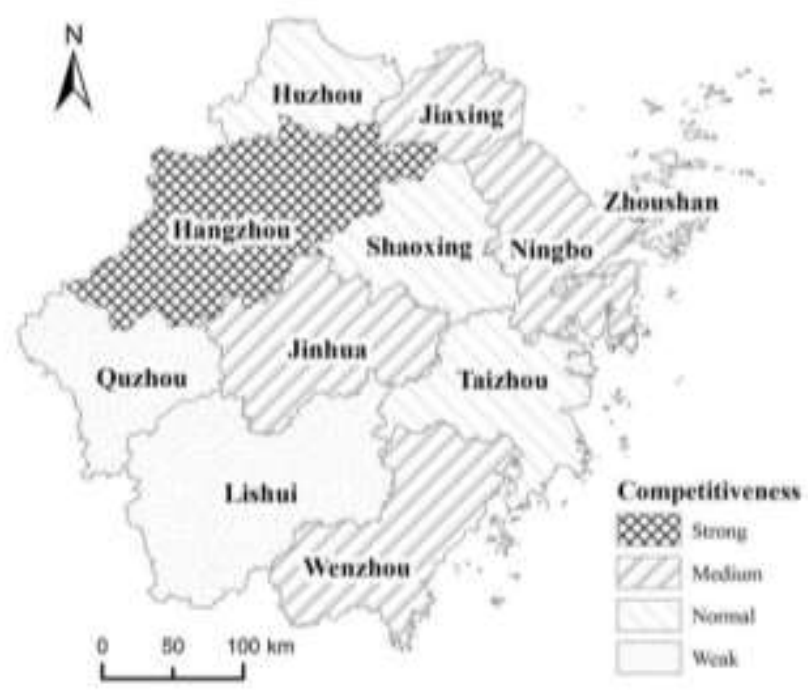

Figure 1: Distribution map of Zhejiang's urban cultural tourism competitiveness

Table 7: Supply - Demand - Support cultural tourism competitiveness ranking

\begin{tabular}{cccccccccccc}
\hline & Hangzhou & Ningbo & Zhoushan & Jiaxing & Huzhou & Shaoxing & Wenzhou & Taizhou & Jinhua & Lishui & Quzhou \\
\hline T1 & 0.3857 & 0.1688 & 0.0142 & 0.1400 & 0.0844 & 0.0894 & 0.1308 & 0.0956 & 0.0891 & 0.0305 & 0.0274 \\
Rank & 1 & 2 & 11 & 3 & 8 & 6 & 4 & 5 & 7 & 9 & 10 \\
T2 & 0.2000 & 0.1184 & 0.0315 & 0.0877 & 0.0622 & 0.0359 & 0.0985 & 0.0504 & 0.1300 & 0.0305 & 0.0091 \\
Rank & 1 & 3 & 9 & 5 & 6 & 8 & 4 & 7 & 2 & 10 & 11 \\
T3 & 0.2855 & 0.2351 & 0.1530 & 0.1016 & 0.0536 & 0.1000 & 0.1914 & 0.0986 & 0.1472 & 0.0845 & 0.0553 \\
Rank & 1 & 2 & 4 & 6 & 11 & 7 & 3 & 8 & 5 & 9 & 10 \\
\hline
\end{tabular}

Numerical results for the four decimal places.

*T1=Tourism supply competitiveness, $\mathrm{T} 2=$ Tourism demand competitiveness, $\mathrm{T} 3=$ Tourism support competitiveness

In order to further analyze the reasons for the strength of the tourism competitiveness of each city, the scores of the three dimensions of urban tourism supply competitiveness (T1), urban tourism demand competitiveness (T2), and urban tourism support competitiveness (T3) are calculated and ranked respectively. Finally, the above Table7 is obtained. Hangzhou ranks first in all dimensions, followed by Ningbo, but lags behind Jinhua in terms of competitiveness in tourism demand, and Jinhua ranks in the middle of the province in the other two dimensions. Jiaxing ranks third in terms of supply competitiveness, with more scenic spots and more cultural venues. Wenzhou ranks 4th in urban tourism supply and demand and supply, and 3rd in support. It can be observed that Ningbo, Jiaxing, Jinhua, and Wenzhou all have the top 3 rankings in one or several dimensions. Zhoushan ranks fourth in the city's tourism support power, with prominent indicators such as air quality and green area, but it ranks low in terms of tourism supply and demand, and tourism supply ranks last. Huzhou, Shaoxing, and Taizhou rank at the middle and lower levels in all three dimensions, while Lishui and Quzhou rank bottom in all dimensions.

\section{Conclusions and Recommendations}

\subsection{Conclusions}

Based on previous research and the situation in Zhejiang Province, this paper constructs an evaluation system for Zhejiang's urban cultural tourism competitiveness, which is divided into 23 indicators in three dimensions, calculated by entropy method, and summed up. At the same time, combined with the original data statistics table and visual map analysis, it turns out that :
(1) Hangzhou has the strongest competitiveness in the first echelon, but it is not in the top three in the "number of stadiums" and "proportion of days with good air quality". (2) Ningbo, Jiaxing, Jinhua, and Wenzhou are in the second echelon. Ningbo ranks in the forefront of comprehensive and all-dimensional scores, but scores lower in cultural venues such as the number of stadiums and theaters, and Jinhua's supply competitiveness is relatively high. Inbound tourists and inbound tourism income indicators are related. Wenzhou's various indicators are also relatively high, but the score in "the number of theaters and theaters" is low, and the standardized value is 0. (3) Taizhou, Shaoxing, Huzhou, and Zhoushan are in the third echelon. Zhoushan has a good performance in tourism support and ecological environment related indicators. Taizhou ranks relatively high in tourism supply. Taizhou has 89 A-level tourist attractions, only Second to Hangzhou, but the number of star-rated hotels, the number of travel agencies, and the number of cultural venues are obviously at a disadvantage; Shaoxing's standardized index domestic tourism revenue growth rate $\%$ and total tourism traffic are 0 , indicating that the attractiveness is average, although the number of A-level scenic spots is not It's a small number, but the number of $4 \mathrm{~A}$ scenic spots ranks low in the province. (4) Lishui and Quzhou are the weakest in competitiveness. They are lower in all dimensions. The public budget of cultural tourism and sports media is low, which is related to the strength and investment of local economy. Lishui's indicators such as "the number of theaters and theaters", "the number of stadiums", "the number of hospital beds", and "the number of inbound tourists" are relatively low, while Quzhou's performance in "the number of travel agencies", "the number of stadiums" and "the number of domestic tourists", "Total social consumer goods" and other indicators are relatively low. 


\subsection{Recommendations}

The competitiveness of urban tourism is affected by many factors. Different cities can build on their strengths and compensate for their weaknesses driven by innovation, and strive to improve their own competitiveness. Combining the original data of the evaluation system, the following suggestions are made:

In the first echelon city, Hangzhou ranks first in most indicators, but it is necessary to pay attention to sports investment, hold large-scale sports events, and explore the "cultural tourism + sports" model to enhance the competitiveness of Hangzhou cultural tourism. The 2022 Asian Games will provide good results. Platforms and opportunities. The ecological environment with air quality as an important indicator is a level that Hangzhou needs to take into account in the development of cultural tourism. It is also a challenge and an important breakthrough in enhancing competitiveness in the Yangtze River Delta and even across the country. At the same time, it is necessary to make full use of the opportunity of Zhejiang Digital Economy No. 1 Project, and do a good job in the digital reform of the cultural and tourism industry. Hangzhou plays a leading role in Zhejiang and leads the development of cities in the province towards digital cultural tourism.

Among the second-tier cities, Ningbo can combine the history and culture of Ningbo to host more cultural activities and sports events relying on cultural venues to further improve the infrastructure construction of cultural venues. Through the indepth integration of culture and tourism, tell the "Ningbo Story" well, and use culture to drive Ningbo's cultural tourism to a higher level. Jiaxing's cultural tourism supply competitiveness is relatively strong, which is related to the fact that there are more A-level scenic spots, especially three $5 \mathrm{~A}$ scenic spots. Jiaxing can make full use of the existing scenic resource advantages, do a good job in cultural tourism product development and marketing, and further increase demand competition force. Yiwu International Trade City was awarded China's first 4A-level shopping area by China National Tourism Administration. Jinhua can make full use of the "cultural tourism + commerce" model to create Jinhua cultural tourism characteristics. In addition to the construction of scenic spots in Wenzhou, emphasis on the integration of culture and tourism is a direction worthy of attention.

Regarding the third-tier cities, it can be started from one of the three dimensions. For example, Zhoushan can have distinct "vacation" characteristics and advantages such as ecological tourism, leisure tourism, and health tourism, increase the selection of quality tourist attractions, and continue to improve and improve Supporting services such as local hotel stars and quality to enhance the core competitiveness of Zhoushan tourism. Taizhou can make full use of abundant tourism resources to further develop global tourism, provide tourism services in combination with online and offline forms, and do a good job in tourism marketing in the new consumption era. Shaoxing has multi-dimensionally enhanced tourism services and experience, and upgraded more $3 \mathrm{~A}$ scenic spots to $4 \mathrm{~A}$, and $2 \mathrm{~A}$ to $3 \mathrm{~A}$ is the focus of Shaoxing's cultural tourism needs to be optimized in the next step. In addition, Shaoxing and Taizhou are geographically bordered by the second-tier cities, and even the core Hangzhou is also bordered by Shaoxing, and the per capita consumption is relatively high. It can make full use of the attractive flow of neighboring competitive tourist cities to enhance tourism demand competition.

For the fourth-tier cities, the economy of Lishui and Quzhou is in a backward position in Zhejiang, and the gap with other cities is very large. While investing in infrastructure, it is suggested to start with the competitiveness of cultural tourism demand, and combine new consumption and new marketing models as options that can be considered. For example, Lishui can dig deeper into the elements of Jinyun Xiandu Scenic Area, and Quzhou combines Jianglang Mountain and Gengong Buddha Country to create Internet celebrity attractions or cultural phenomena. Through live broadcasts and short videos, the visibility of cultural tourism will be further enhanced, and the competitiveness of urban cultural tourism will be enhanced.

\section{Acknowledgments}

Project source: Shaoxing City's Philosophy and Social Science Research "14th Five-Year Plan" key project research on Shaoxing's cultural, business, tourism, agricultural and sports integration development and city image enhancement under the innovation drive (145066).

\section{References}

[1] William F. Lever. Competitive Cities: Introduction to the Review[J]. Urban Studies, 1999, 36(5-6).

[2] L Dwyer. Destination Competitiveness: Determinants and Indicators: Current Issues in Tourism [J]. Current Issues in Tourism, 2003, 6(5): 369-414.

[3] Crouch G I, Ritchie J. Tourism, Competitiveness, and Societal Prosperity[J]. Journal of Business Research, 1999, 44(3): 137-152.

[4] Gilbert D, Tung L. Public organizations and rural marketing planning in England and Wales[J]. Tourism Management, 1990, 11(2): 164-172.

[5] Ma Yong, Dong Guanzhi. Research on the Potential Model of Regional Tourism Sustainable Development[J]. Tourism Tribune, 1997(04): 36-40+62.

[6] Zhang Heqing, He Yifei, Tian Xiaohui. Research on the Evaluation System of County Tourism Competitiveness in Guangdong Province[J]. Economic Geography, 2012, 32(09): 172-176.

[7] Song Rui. The development environment and core propositions of my country's tourism industry during the "14th Five-Year Plan" period[J]. Tourism Tribune, 2020, 35(06): 1-3.

[8] Xie Ruijin, Hu Yunhong, Zhang Heng. Evaluation of Shanxi Province's Urban Cultural Tourism Competitiveness Based on Grey Evaluation Model[J]. Mathematics in Practice and Knowledge, 2020, 50(06): 256-263.

[9] Xu Chunhong, Shu Weiying. Evaluation of the tourism industry competitiveness of the Bay Area under the background of high-quality development: Based on a comparative study of the Hangzhou Bay and Guangdong-Hong Kong-Macao Bay Areas[J]. Journal of 
Southwest China Normal University (Natural Science Edition), 2021, 46(03): 57-63.

[10] Xiong Zhenqin, Tang Jinli, Hong Xiuli. A Comparative Study on the International Competitiveness of China-US Tourism Service Trade[J]. Asia-Pacific Economics, 2019(05): 85-93+151.

[11] Shi Xiangxiang. Research on Dynamic Evaluation of Urban Tourism Competitiveness in Central China[J]. Journal of Southwest China Normal University (Natural Science Edition), 2019, 44(10): 40-48.

[12] Li Chunying, Lin Caibin, Lin Mingshui, Ke Yingying. Research on the Evaluation of County-wide Tourism Competitiveness: Taking Fujian Province as an Example [J]. Journal of Fujian Normal University (Natural Science Edition), 2020, 36(04): 81-92.

[13] Zhu He, Liu Jiaming. Research on the Competitiveness of Tourism in Eastern China-Based on Time Series
Global Principal Component Analysis [J]. Regional Research and Development, 2015, 34(05): 100-104.

[14] Zhang Chunxiang. Research on the Evaluation of Regional Cultural Tourism Industry Competitiveness Based on Diamond Model[J]. Chinese Journal of Management, 2018, 15(12): 1781-1788.

[15] Zhao Shuhong, Bai Meng. Analysis of the coupling and coordination characteristics and influencing factors of brand tourism resource competitiveness and tourism flow in Yunnan Province[J]. Geographical Sciences, 2020, 40(11): 1878-1888.

[16] Zhang Zhen, Liu Jia. Evaluation of China's provincial online tourism competitiveness and identification of development types[J]. Statistics and Decision, 2020, 36(22): 185-188.

[17] Liu Qing. Evaluation and improvement path of ChinaASEAN tourism service trade competitiveness [J]. Economic Issues, 2019(11): 112-119.

\section{Appendix}

Standardized index values of 11 cities

\begin{tabular}{|c|c|c|c|c|c|c|c|c|c|c|c|}
\hline & Hangzhou & Ningbo & Zhoushan & Jiaxing & Huzhou & Shaoxing & Wenzhou & Taizhou & Jinhua & Lishui & Quzhou \\
\hline C1 & 1.0000 & 0.3492 & 0.0000 & 0.6984 & 0.5714 & 0.6508 & 0.5556 & 0.7778 & 0.5397 & 0.3651 & 0.3651 \\
\hline $\mathrm{C} 2$ & 1.0000 & 0.7798 & 0.0000 & 0.2844 & 0.1560 & 0.2752 & 0.5963 & 0.1560 & 0.1927 & 0.1009 & 0.0459 \\
\hline $\mathrm{C3}$ & 1.0000 & 0.3456 & 0.1077 & 0.1491 & 0.1183 & 0.1231 & 0.1183 & 0.0201 & 0.0592 & 0.0118 & 0.0000 \\
\hline C5 & 0.5385 & 0.3269 & 0.0000 & 1.0000 & 0.7692 & 0.5385 & 0.6154 & 0.1346 & 0.1731 & 0.2115 & 0.0000 \\
\hline C6 & 1.0000 & 0.0368 & 0.0552 & 0.3252 & 0.1840 & 0.0184 & 0.0000 & 0.4479 & 0.4049 & 0.0000 & 0.0920 \\
\hline C7 & 1.0000 & 0.3626 & 0.0223 & 0.2761 & 0.0576 & 0.2272 & 0.4082 & 0.2555 & 0.1221 & 0.0000 & 0.0497 \\
\hline C9 & 1.0000 & 0.6691 & 0.1288 & 0.4988 & 0.2206 & 0.1254 & 0.5101 & 0.1131 & 0.7825 & 0.0000 & 0.0009 \\
\hline $\mathrm{C} 10$ & 1.0000 & 0.5442 & 0.1096 & 0.4191 & 0.1980 & 0.0938 & 0.4296 & 0.0563 & 0.7205 & 0.0000 & 0.0014 \\
\hline C11 & 1.0000 & 0.5062 & 0.0000 & 0.3617 & 0.4514 & 0.3253 & 0.4859 & 0.4483 & 0.5037 & 0.0563 & 0.0617 \\
\hline $\mathrm{C} 12$ & 1.0000 & 0.5085 & 0.1241 & 0.2400 & 0.2751 & 0.2105 & 0.2781 & 0.2596 & 0.2822 & 0.0554 & 0.0000 \\
\hline C13 & 0.8407 & 0.5841 & 0.5310 & 0.6018 & 0.5398 & 0.4248 & 0.8496 & 0.6549 & 0.8938 & 1.0000 & 0.0000 \\
\hline C14 & 1.0000 & 0.8516 & 0.5000 & 0.7891 & 0.5625 & 0.0000 & 0.8359 & 0.5859 & 0.8906 & 0.8906 & 0.5078 \\
\hline C15 & 0.8990 & 0.8131 & 0.6844 & 1.0000 & 0.8902 & 0.6946 & 0.6061 & 0.4741 & 0.4804 & 0.0014 & 0.0000 \\
\hline C16 & 1.0000 & 0.6580 & 0.0000 & 0.2876 & 0.1486 & 0.2907 & 0.5489 & 0.3509 & 0.3825 & 0.2575 & 0.0355 \\
\hline C18 & 0.8168 & 0.4085 & 0.1555 & 0.1284 & 0.1538 & 0.0000 & 1.0000 & 0.3322 & 0.4942 & 0.0654 & 0.1037 \\
\hline C19 & 1.0000 & 0.9384 & 0.0000 & 0.5112 & 0.0964 & 0.2962 & 0.3249 & 0.2202 & 0.3193 & 0.0052 & 0.0016 \\
\hline $\mathrm{C} 20$ & 1.0000 & 0.4079 & 0.0273 & 0.0959 & 0.0555 & 0.1379 & 0.4943 & 0.0867 & 0.1926 & 0.0005 & 0.0000 \\
\hline $\mathrm{C} 21$ & 1.0000 & 0.6396 & 0.6193 & 0.6210 & 0.4598 & 0.7772 & 0.5512 & 0.5168 & 0.7957 & 0.2027 & 0.0000 \\
\hline $\mathrm{C} 22$ & 0.0000 & 0.7550 & 1.0000 & 0.1139 & 0.0124 & 0.1559 & 0.0124 & 0.1139 & 0.1114 & 0.3168 & 0.2104 \\
\hline $\mathrm{C} 23$ & 0.0888 & 0.4860 & 0.9346 & 0.1542 & 0.0000 & 0.4346 & 0.9486 & 0.5561 & 0.5654 & 1.0000 & 0.7804 \\
\hline
\end{tabular}

